\title{
Analysis of growth patterns in purebred kambing Katjang goat and its crosses with the German fawn.
}

\begin{abstract}
The objective of this study was to investigate growth patterns of goats utilizing data from a crossbreeding program involving the exotic German Fawn (GF) and the indigenous Kambing Katjang (KK) goats. Growth curve models and growth curve parameters were compared and analyzed for different genotypes and litter types. A total of 20,393 weight-age data from 208 female goats belonging to various crossbreeding genotypes were individually fitted to four growth curve models (Brody, Bertalanffy, Gompertz and Logistic). The goodness of fit was highest in the Brody model in most cases. A comparison of R2 among genotypes showed that they were highest for KK. There were no significant differences of genotypes for estimated mature weight in the Brody model. The estimated mature weights for KK were significantly lower $(\mathrm{P}<0.05)$ than for GF $\times \mathrm{KK}(\mathrm{F} 1)$, backcrosses with $75 \%$ GF genes $(\mathrm{BC})$ and $\mathrm{F} 1 \times \mathrm{F} 1$ (F2) in the other models. The correlations between estimated mature weights and the maturing rates were lowest for $\mathrm{BC}$. The genotype significantly $(\mathrm{P}<0.01)$ affected the age at the constant degree of maturity (67\% and $90 \%$ of mature weight) in all models. The BC genotype was the youngest at maturity and KK the oldest. All models well expressed the growth pattern of the target animals when they were older than 2.5 years of age. The results from the present study showed that the growth pattern may be altered by crossbreeding of KK with the GF breed.
\end{abstract}

Keyword: Kambing katjang; German fawn; Growth pattern; Crossbreeding; Growth curve models. 